programmes for high schools, forum plans for colleges and universities, forum plans for youth on community-wide basis and "guide-posts to organisation".

Some of the problems of "Forums for Young People" were discussed at the Secondary School Conference held by the Association for Education in Citizenship last year at Morley College, London. A report of the proceedings at this conference appeared in the July number of the Citizen. The conference covered a wider field, including consideration of the part played by character and purpose in the making of good citizens, and the efficacy of various out-ofschool activities such as scouting, classes in first-aid, and camping as means for stimulating emotion and imagination and harnessing them to action in the service of the community so as to overcome "that apathy which is the besetting weakness of democracy". With the view of keeping in touch with one another the now considerable number of schools where systematic efforts are made to foster the development of a spirit of community service a "Schools Community Service Group" has been constituted within the Association with headquarters at
The Downs School, Colwall, Malvern, with Mr. W. F. Hoyland as honorary secretary. The chief subjects dealt with by the group are : manual work on the school estate, help at physical training and play centres, boys' clubs and school missions, visits to factories, housing estates, etc., work camps in the holidays, for example, helping unemployed men on their allotments, school expeditions abroad.

In the same number of the Citizen is an article of outstanding interest by Prof. René Maheu of the Institut Francais du Royaume-Uni on the teaching of philosophy in French secondary schools. The philosophy teachers are, it appears, allowed the greatest freedom both as to method and as to subject, and most of them concentrate on instruction "not so much in facts or ideas as in the sovereign art of passing judgment". 'They seek to equip their pupils with the techniques of self-knowledge and of objective thinking. To them is available the sole opportunity given to secondary school teachers of "effectively helping their pupils to decide for themselves with their own reasoning powers, the use they are to make of their freedom as citizens".

\title{
The Differential Analyser in Electrical Engineering
}

$\mathrm{I}^{\mathrm{N}}$ recent years, there has been a considerable development in the design and use of mechanical and electrical instruments for carrying out calculations of various kinds. These calculations can be irvided into two main groups : first, there are those which consist of the four processes of arithmetic (addition, subtraction, multiplication and division) combined in any way, and secondly there are those which involve the further ideas of the calculus. For the latter group of calculations, the solution of differential equations is one of special importance both in pure and in applied science, as in both fields there arise many kinds of differential equations which have no formal solution or none convenient for numerical evaluation, but for which quantitative information about the behaviour of the solution is required.

In a paper by Prof. D. R. Hartree and Mr. J. K. Nuttall on the differential analyser and its applications in electrical engineering ( $J$. Inst. Elec. Engineers, No. 503), a description is given of the differential analyser, and it is shown that the solutions of nonlinear differential equations can be readily obtained by its use. Although it is possible to evaluate the solutions of such equations numerically and sometimes graphical methods can be employed, yet except for simple equations, numerical methods are laborious and lengthy, and graphical methods are limited in scope and accuracy and are also laborious to carry out on a large scale. The general idea of such a machine was due to Lord Kelvin. The practical realization of the idea is due to Dr. V. Bush, of the Massachusetts Institute of Technology, where the first machine of this kind was designed and construoted. A similar machine built by the MetropolitanVickers Electrical Co., Ltd., is installed at the University of Manchester and there is another at the University of Pennsylvania.

Immediately following the paper describing the differential analyser, there is an excellent account of the practical application of it to study the transients on a distortionless transmission line, by Prof. Hartree and Dr. Porter. The ever-increasing volume of technical literature on lightning and its effects on transmission lines and terminal equipment provides evidence of the attention now being paid by engineers to this problem. It is now known that the severity of a transient occurring at a line terminal may be lessened by flattening the front of the wave, by means of wave modifiers or surge absorbers or by reducing its amplitude by means of 'arresters' of various types. The principal features of the majority of arresters of the 'spillover' type is that their action depends on the use of a material having a non-linear current-voltage characteristic.

This paper describes the solution of the problem of evaluating the history of a transient on a finite line with such a non-linear impedance at one or both ends. The behaviour of a transient on a finite distortionless line can be described in terms of two travelling-wave systems propagated in opposite directions along the line. The voltages in these two waves satisfy two ordinary differential equations depending on the terminal conditions, and involving a relation between the voltage at two times differing by the time of travel of a wave from one end of the line to the other and back. Equations of this type can be handled mechanically by means of the differential analyser, and the use of the differential analyser does not require that the terminal impedances should have linear characteristics. The authors apply the instrument to a line with a capacitance at one end and a non-linear resistance (lightning arrester) at the other. Specimens of machine solutions, both with a linear and a non-linear resistance at the far end, are given and discussed, and compared with oscillograms taken on an actual line. 